Journal of Social Sciences 8 (3): 407-411, 2012

ISSN 1549-3652

(C) 2012 Science Publications

\title{
The Application of Interpersonal Relationship Poll to the Enhancement of Management Efficacy
}

\author{
Kuo-Wei Lin and Wen-Chi Ku \\ Department of International Business, \\ Hsuan Chuang University Hsinchu, 30092, R.O.C., Taiwan
}

\begin{abstract}
Problem statement: Every employee needs to directly face their different superiors and subordinates that he must have ability to get along with other people or teams. It is the ability that he could communicate, coordinate, convince, negotiate and inspire his working partners smoothly and the organization, leadership and control could be implemented in accordance with the established plans. So the interpersonal relationship of employees may severely affect an organization. Although many enterprises have developed their own assessment systems, most of the systems focus on performance evaluation and few of them explore the efficacy of organization from the angle of employee's interpersonal relationship. Approach: This study aims to develop a well-rounded model for the interpersonal relationship poll that every employee could receive poll for his own interpersonal relationship. Through the questionnaire poll that includes self-assessment and other's assessment, one could systematically and methodically see himself from the eyes of others and understand whether he is an asset or a liability in the operation of organization, a resistance force or a boosting force that he could modify his own interpersonal relationship and in turn enhance the operational efficacy in organization. Results: The model for interpersonal relationship poll developed by the study has been practically applied. After an employee understand his working partners' views on him in the poll, his relationship with other colleagues is improved and his performance is enhanced. Conclusion: The interpersonal relationship poll made full use of the approaches in raising questions to the persons involved for self-evaluation and assessed by others, jumped out passive and slow one-way selfexamination and turned to positive, quick two-way communications that were substantially helpful in harmonizing interpersonal relationship and enhancing the operational efficacy in organization.
\end{abstract}

Key words: Interpersonal poll, interpersonal relationship, operational efficacy, systematically and methodically, individual image

\section{INTRODUCTION}

The employee's interpersonal relationship may have severe impact on the operation and effectiveness and efficiency. In a modern enterprise, one of most important evaluation items for selecting and promoting personnel is excellent interpersonal ability. Therefore, if an independent individual in the study could harmoniously integrate into the group and the operation of organization, the efficacy of organization will be enhanced.

In the three skills that Katz (2009) suggested for a manager, one is human skill. With the excellent skill, he could implement substantial communications including coordination, convincing and negotiation and lead other employees to achieve the goals of organization, establish internal and external relationship of organization. The research by Lin et al. (2007) confirmed that if a leader took democratic and supportive attitude as his leadership style and was happy to face the questions and challenges, the interactions with the members would produce the sense of more security in the team. The research by Tsai and Shueh (2007) also confirmed that the satisfaction from the communications in the organization had signification correlation with the business operation management, financial structure, human resource planning and service quality in the performance of organization. So it is proved that the satisfaction form an effective communication may achieve better commitment of organization and in turn enhance the efficacy of organization.

Corresponding Author: Kuo-Wei Lin, Department of International Business, Hsuan Chuang University Hsinchu, 30092, R.O.C., Taiwan 


\section{J. Social Sci., 8 (3): 407-411, 2012}

Marquardt (2005) argued that through appropriate questions, an enterprise could receive useful information and understand interpersonal relationship in the organization that could stimulate an enterprise's ability to innovate and improve the work efficiency. Therefore, the purpose of the study is to develop a model for interpersonal relationship poll that allows every employee to receive his own interpersonal relationship poll. Through questionnaire surveys, one could systematically and methodically see himself from the eyes of others, understand whether he is an asset or a liability in the operation of organization, a resistance force or a boosting force that he could improve his relationship with colleagues and in turn enhance his own performance.

\section{MATERIALS AND METHODS}

Because the purpose of the study is to develop interpersonal poll model to enhance the efficacy of organizational operation, it is necessary to follow up the following theories.

The formation of self-conception: So-called selfconception is the individual understanding of oneself. DeVito (2010) stressed that the sources of formation: (1) self-assessment: recognize oneself through his own sensory perception, emotional reactions or explicit behaviors, such as what is interested in and what is the fear. (2) Others' response: that is, others' feedback response to the one's behaviors that has been conveyed to others through external expression, such as others' praises or disgust. (3) social comparisons: means the cognition of relationship between oneself and others through comparing with others, such as tall and short, beautiful and ugly and superior and inferior; (4) cultural cultivation: means the norms and values given by the society, such as the standards of ethics. Once the selfconception is formed, it is not easy to change and may selectively receive message. Because it is not objective, for avoiding effects of wrong self-conception on right interpersonal interactions, keeping communications with others and correcting and finding right selfconception are very important. Right self-conception often positively affects one's own achievements that Paige (1993) mentioned that U.S. President Barack Obama is a person who can correct his self-conception at any time. He said that Obama can always precisely understand and accept different viewpoints, quickly find out best way to achieve the goals and he is a good example that can adjust self-conception and use good self-conception to achieve great cause.

Johari window: Josph (1982) stressed that when the work went not well, one better to use Johari Window to examine the relationship between his own behaviors and others. Luft argued that four quadrants (Fig. 1) divided by two dimensions, known (or not known) to self and known (or not known) to others can adjust one's own interpersonal relationship. The open area represented by Quadrant I means one is willing to reveal information to others, such as one's own attitude or thinking that is the part known to self and others; Quadrant II is blind area that means the blind part of self-conception, such as the habitual actions or disgusting behaviors that are not known to self. That is the part known to others but not known to self and is related to whether one is prone to note or accept feedback from others; Quadrant III is hidden area that means individual's hidden secrets and thought, such as negative behaviors including drugs or stealing. That is the part known to self but not known to others; Quadrant IV is the mystery area, means the potentials not known to self or depressed memory. That is the part neither known to self nor known to others.

Hamachek (1992) argued that the focus point of interpersonal relationship lied in the feeling of relationship between self and others. How to conclude and constrain the relationship self-conception and others, how to deal constructively with others' psychological impression of self has significant relationship with the how one emphasizes on selfesteem because through others, one could see self that is not known and that is the right way to maintain the feeling. Luft argued that the smaller opening oneself is, the worse interpersonal communication will be because if one not open himself, how could he expect others to understand him and establish relationship with him. So one should share with others (Fig. 2), promote others' understanding of him, win over others' identification and reduce hidden area. Besides, Luft also proposed that one should understand his own disadvantage and missing from the information (Fig. 3 ) given by others' feedback and try to correct and reduce blind and mystery area.

360 Degree feedback: Edwards and Ewen (1996) introduced 360 degree feedback evaluation model very early.

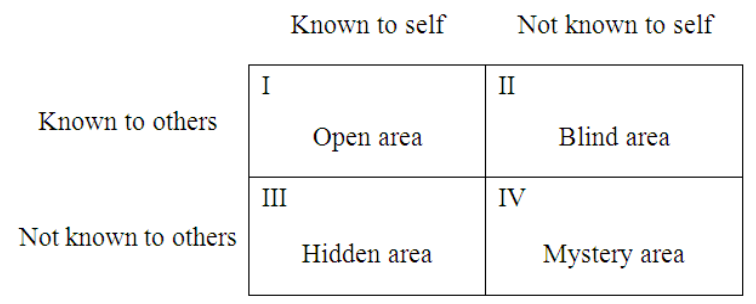

Fig. 1: The Johari Window 


\section{J. Social Sci., 8 (3): 407-411, 2012}

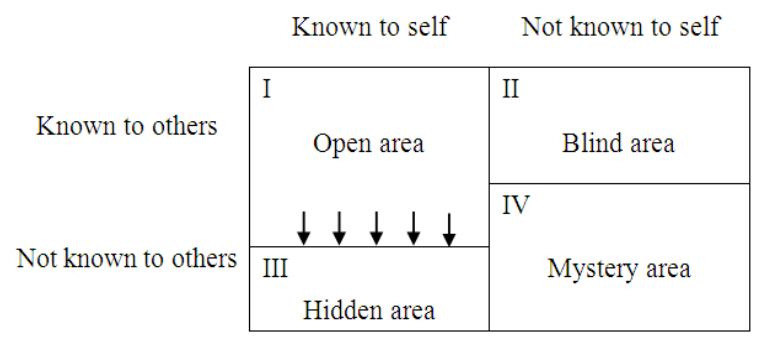

Fig. 2: Share Self to Others

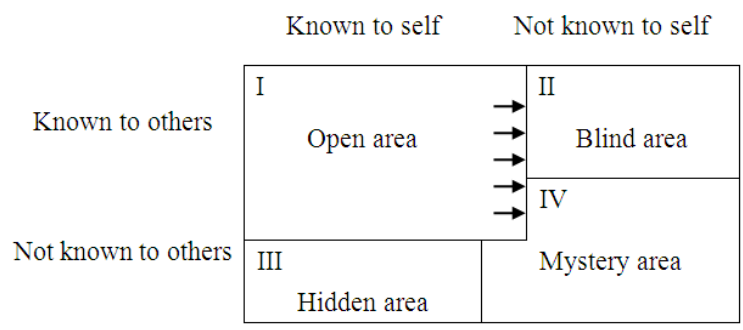

Fig. 3: Feedback from Others

The model collects evaluation information from direct superiors, colleagues, subordinates, external customers and self before comprehensive analysis and judgment. It could avoid assessment error due to unfamiliarity with the evaluated by the managers and more precisely and fairly evaluate employees' performance, that is, the degree of efforts to achieve organizational goals. Besides, Roberto (2005) also mentioned that when a leader observes the inclination of indecisiveness in the organization, he could use 360 degree feedback to understand the interactive relationship between himself and other executives and colleague's views on him as the first step to change the corporate culture. He should also set himself as an example to build constructive communication; gradually change the interactive relationship with his subordinates through the 360 degree feedback that could affect the atmosphere of entire organization.

Interpersonal poll: That is using questionnaire survey to conduct a poll of one's own interpersonal relationship in which through self-assessment and assessed by others, one can see himself from others' eyes in a systematic and organized way. Because most of people cannot see their own advantage and disadvantage and potential problems, they may lose his interpersonal competitiveness and precious interpersonal wealth. According to results of interpersonal relationship survey in workplaces by the website constructed by the study for interpersonal poll (http://tolove.com.tw/admin.php): $1.48 \%$ of employees dislike their superiors while $2.54 \%$ feel that their colleagues or superiors do not recognize their ability. $3.64 \%$ said their colleagues or superiors pay no attention to their friendship. $4.70 \%$ stressed that unfriendly colleagues or superiors may bring him disadvantageous effects. $5.63 \%$ believe that their colleagues and superiors do not understand them while $48 \%$ confess that they do not understand their colleagues or superiors. Lastly, 54\% also confessed that they are not positive enough in operating workplace interpersonal relationship. Such results show that the predicaments the employees face are embarrassed and weak. So the evaluation of interpersonal poll could turn the disturbances on interpersonal relationship into twoway and benign interactive communication from passive and one-way self-examination and reduce Luft's hidden, blind and mystery area in Johari Window while expand open area. We can also use 360 Degree feedback evaluation to deeply re-recognize ourselves, initiatively and preventively clear the obstacles of interpersonal communications to enhance the functions of organizational operation.

Methods: this study uses questionnaire survey and is a individual poll that adopts non-random purposive/judgment census method. So the measurement tool used in the survey is interval scaled questionnaire in which the scores are totalized to measure the abstract conception. So how to design a right questionnaire to measure workplace interpersonal relationship is the necessary core value in interpersonal poll. Although the interpersonal relationship include multi-dimensions and complexity, it does not mean each interpersonal dimension is indivisible. Besides, from the experiences of research on 360 Degree Feedback, we learned that testing all dimensions at one time, its' validity may not be brought to full play. Therefore, the dimension adopted for evaluation in interpersonal poll could be decided and adjusted by the surveyed themselves. It is inclined to measure one interpersonal relationship per time. Besides, because the case of interpersonal poll has self-perceived active force, the effect of being not objective is less likely in the selection of samples for assessment by others. Most of samples for assessment by others are invited by the surveyed. The number of invited samples for assessment by others will show as plural in the workplace relation. There is no limit on maximum number for assessment by others. In filling the questionnaire, the surveyed who is self-assessed fills in a self-assessment questionnaire while the surveyed who assesses others fills in another questionnaire and then cross-analyze the results. 


\section{J. Social Sci., 8 (3): 407-411, 2012}

\section{RESULTS}

The study began to conduct the survey of interpersonal relationship after completing the construction of structure of interpersonal poll questionnaire. The subject was a computer and information engineer with a SME, male, 20 years old, studying in an institute of technology at nights. With flat organization, the company is in the service sectors. The subject is responsible for the maintenance and operation of computer and information in the company and his contents of job are different from other colleagues. However, because he needs to help clients set up websites and teaching, he has plenty of opportunities to contact with internal and external clients.

This was a big challenge for the subject who was familiar to equipment and technology. The purpose of survey focused on the colleagues in the company. Of the colleagues, six of them had direct contact with the subject in daily business and four had indirect contact. A questionnaire survey was conducted and the contents of questionnaire were divided into six question groups: individual image, workplace, customization, cognition of getting along with others, overall recommendations and apparent recommendations. The survey went through discussion with the subject, revision of questionnaire, confirmation of questionnaire, filling in questionnaire, retrieve of questionnaire, re-organization of questionnaire, supplementary filling of questionnaire, compiling statistics of questionnaire and writing report, submitting report and collecting opinions from participants and feedback to the subject. Followings are the results and findings of the survey.

\section{DISCUSSION}

Question group of individual image: (1) In the adjectives of image, we saw an interesting situation: the adjectives of impression that received the first highest votes in the assessment by others, such as relaxed and easy, everybody's clown and simple and kind-hearted, did not appear in the adjectives of self-assessment by the subjects, while none of the ten persons who gave assessment of subject did not pick any of the adjectives of impression that the assessed persons avowed, such as stick to the principle and the spirit of adventure. That meant the cognition of self-impression of the subject was different from the persons who gave the assessment of the subjects. (2) Total 59 questions about individual images. Among which, there were gaps in attitudes in 18 questions of self-assessment and assessment by others, such as no self-confidence, the subject assessed himself as less self-confidence whereas seven of persons who gave assessment of subject said that they felt self-confidence of the subject and the other three said that they felt strong confidence of the subjects. The other assessments, such as patience, self-esteem, selfcontrol, gregarious, showed the subject and persons who gave assessments of the subject held opposite views. (3) Through the question of adjectives of advantage and disadvantage, the subject surprised to know he had many advantages from the eyes of his colleague. The top three advantages in order were strong adaptability, professional and optimistic, but the advantages, knowing how to fulfill others' dream and down to the earth, the subject thought he had were not picked by others.

Performance in Workplace: On the part of performance in workplace, 11 questions in total 27 questions, there were gaps of scores between the selfassessment and assessment by others. That meant the subject and the persons who gave the subject assessment had different views on the scores, for example, on the tactfulness in dealing with the various situations, the subject graded four points whereas two of the others gave subject three points and four gave two points.

Customization: Customization question is a question that simulates the workplace situation and is the concerns that the subject worries in getting along with the colleagues. The questions are: when your colleague asks you to support a business, but you are busy in other business in hand, the first question is, in your intuition at this point, will you feel he is annoying? We found eight of colleagues answered no. The second question is what will you say to him? The results are: ask him to wait, finish the work in hand first or tell him you don't have time. The last question is: how do you handle such situation? The answers are: try your best to help him or explain your difficulty.

Cognition of getting along questions: The cognition of getting along questions partly emphasize on what subject's habits that the colleagues may pay attention to in working with the colleagues for long-time. They are easy and interesting question group with the purpose to test the tacit agreement. The results found that there were some or more or less gaps. But when a question asking the subject what he most often eat for lunch, all colleagues answered "instant noodles". It is impressive because the lunch is the meal that the employees most closely interacted. The subject was also very surprised and happy to know his colleague care about and pay attention to him. 
Personal overall advices: This is an open question. Through the question, the subject obtained concrete advices including think over in your heart before make decision for anything and should not too impulsive; eat less instant noodles, do more physical exercise; put on facial mask, more sleep and rest; enrich yourself; more tender language in communications that others will love to talk to you more and speak soberly; more laugh; a talent worthy of cultivation.

Advices for personal appearance: They are recommendations for individual's appearance and dress. It is also open question. Through the questionnaire, the subject obtained the concrete recommendations including need to improve on the part of neat; too slovenly; wearing younger and lively; wear pink shirt instead of elderly tone of deep purple-gray.

The test of research not only provided the subject with many valuable opinions in dealing with people and various situations but also help the subject love others and the others also like the subject that the subject has immersed all day in a harmonious and pleasant atmosphere and thus greatly enhanced the working efficiency.

\section{CONCLUSION}

The results of above-mentioned case confirmed that indeed the interpersonal poll questionnaire could correctly measured the interpersonal relationship of subject and functioned as a collector of other assessors' views and comments on the subject. In the survey of workplace relationship, the goodness of fit between the views of self-assessment and assessment by others in the study reached up to $70 \%$ and provided the subject with reference values for the remaining $30 \%$ of views in which the self-assessment and assessment by others were not consistent. Certainly, a careful subject could also learn from the report of results that on some items, despite the same attitude, there was the difference of degree from others' views. The knowledge could be used for the adjustment of cognition of self-conception. Therefore we obtain following five conclusions.

Everyone's interpersonal relationship will generate blind spots of relationship with others.

The quantified questionnaire survey method in public sphere has the same effect and meaning if it is used on the individual's interpersonal relation in private sphere.

Interpersonal poll makes full use of questioning approach for the self-assessment and assessment by others of stakeholders, jumping out the passive, slow one-way reflection ant turning to the positive and quick two-way communications. It is substantially helpful to the improvement of the harmoniousness of various interpersonal relationship.
We can also create a personal exclusive interpersonal relationship-related file that will has additional functions of being introspective inside and showing good faith outside.

Through interpersonal poll method, it can indeed find out a direction to solve concrete problems for abstract interpersonal relationship. Therefore, this study strongly proposes that the best way to solve the employee's interpersonal troubles in workplace is using interpersonal poll to allow each employee accept opinions poll of his own interpersonal relationship. By means of questionnaire survey and through results of self-assessment and assessment by others, one could systematically and methodically see himself from the eyes of others and understand whether he is an asset or a liability in the operation of organization, a resistance force or a boosting force that he could modify his own interpersonal relationship and in turn enhance the operational efficacy in organization.

\section{REFERENCES}

DeVito, J.A., 2010. Interpersonal Messages: Communication and Relationship Skills. 2nd Edn., Allyn and Bacon, Boston, ISBN-10: 0205688640, pp: 316.

Edwards, M.R. and A.J. Ewen, 1996. 360 Degree Feedback: The Powerful New Model for Employee Assessment and Performance Improvement. 1st Edn., AMACOM, pp: 256.

Hamachek, D.E., 1992. Encounters with the Self. 4th Edn., Wadsworth Thomson Learning, Belmont, CA., ISBN-10: 0030557445, pp: 382.

Josph, L., 1982. The johari window: A graphic model of awareness in interpersonal relations. NTL institute.

Katz, R.L., 2009. Skills of an Effective Administrator. 1st Edn., Harvard Business School Press, Boston, ISBN-10: 1422147894, pp: 77.

Lin, M.J.J., H.C. Lin, C.H. Hwang and H.J.T. Lin, 2007. The impact of of leadership on team learning: The mediating role of team psychological safety. Hua J. Manage., 8: 1-22.

Marquardt, M.J., 2005. Leading with Questions: How Leaders Find the Right Solutions By Knowing What To Ask. 1st Edn., John Wiley and Sons, ISBN-10: 0787977462, pp: 216.

Paige, R.M., 1993. Education for the Intercultural Experience. 2nd Edn., Intercultural Press, Yarmouth, ISBN-10:1877864269, pp: 315.

Roberto, M.A., 2005. Why great Leaders Don't Take yes for an Answer: Managing for Conflict and Consensus. 1st Edn., Wharton School Publication, Upper Saddle River, N.J., ISBN-10: 0131454390, pp: 278.

Tsai, C. and Y.C. Shueh, 2007. The study of the relationship between communication satisfaction, organizational commitment and organizational performance: Social welfare charity foundation as example. Chung Hua J. Manage., 8: 23-42. 